\title{
Shrinkage and Creep of SCC - the Influence of Paste Volume and Binder Composition
}

\author{
Andreas Leemann, Pietro Lura, Cathleen Hoffmann and Roman Loser \\ Empa, Dübendorf, Switzerland
}

\begin{abstract}
Although the use of self-compacting concrete (SCC) is widespread nowadays, relatively few data about its stress-strain-behaviour are available. In this project, the influence of paste volume and cement type (CEM I $42.5 \mathrm{~N}, \mathrm{CEM}$ II/B-M (V-LL) $32.5 \mathrm{R}$ and CEM III/B 42.5 L-LH HS) on shrinkage, creep and stress development under restrained conditions is investigated using three SCC mixtures and three mixtures of conventionally vibrated concrete (CVC) with identical water-tocement ratio. Furthermore, E-modulus and strength are measured. SCC reaches lower values for E-modulus, compressive and tensile strength. While shrinkage is dominated by the volume of paste, with SCC showing higher values than $\mathrm{CVC}$, the influence of cement type plays a more important role regarding creep. Mixtures with higher free shrinkage develop higher stresses and cracked under restrained conditions. Composite models are able to confirm that the differences in E-modulus and shrinkage between CVC and SCC are caused by the differences in paste volume.
\end{abstract}

\section{Introduction}

Cracking, deflection and prestress loss in concrete structures are dependent on the interaction of stress and strain. The established stress-strain relations of conventionally vibrated concrete (CVC) have to be reconfirmed with self-compacting concrete (SCC). The main differences in the mix design are the higher paste volume of SCC, the use of mineral additions and high dosages of superplasticizer, often in combination with a viscosity-modifying agent. These changes can be expected to influence the visco-elastic properties of the concrete.

Compared to CVC, total shrinkage of SCC is increased due to its higher volume of paste [1-3]. The replacement of cement with limestone powder, fly ash or slag leads to a reduction of shrinkage [3-6]. Only silica fume seems to increase shrinkage [6]. It is difficult to draw general conclusions about the influence of binder type and paste volume on shrinkage and creep, as in different studies applied methods and mix design vary in a wide range. Heirman et al. [7] found higher creep coefficients for SCC compared to CVC. On the other hand, Turcry et al. [8] determined similar creep strain for CVC and SCC. Generally, creep coefficient and specific creep seem to be slightly higher for SCC compared to CVC [3,9]. The use of limestone powder can increase creep strain [4], the use of slag or fly ash seems to decrease it $[3,7]$. 
However, an assessment of influence of paste volume and binder type on the properties of CVC and SCC is often hindered by differences in water-to-binder ratio or grain size distribution of the aggregates in CVC and SCC respectively.

This study focuses on the effect of cement type and paste volume on shrinkage under restrained conditions. Three CVC and three SCC using three different cement types (CEM I 42.5 N, CEM II/B-M (V-LL) 32.5 R and CEM III/B 42.5 L-LH HS) were produced. Water-to-cement ratio $(\mathrm{w} / \mathrm{c})$ and grain size distribution of the aggregates were identical for all concrete mixtures. Stress development under restrained conditions was measured. Additionally, creep, shrinkage, E-modulus, compressive and flexural strength were determined. In a further step, composite models were used to calculate the influence of paste volume on E-Modulus and shrinkage.

\section{Materials and Methods}

As binder an ordinary Portland cement (CEM I $42.5 \mathrm{~N}$ ), an ordinary Portland cement with limestone powder $(\sim 14$ mass- $\%)$ and fly ash $(\sim 18$ mass- $\%)$ and an ordinary Portland cement combined with slag ( $\sim 70$ mass-\%). Cement composition is shown in Table I. The aggregates consisted of alluvial sand and gravel (0-4 mm: 32 mass \%, 4$8 \mathrm{~mm}$ : 16 mas- $\%, 8-16 \mathrm{~mm}: 17$ mass $\%, 16-32 \mathrm{~mm}: 35$ mass \%). Water absorption according to EN 1097-6 was between 0.6 and $1.2 \%$ for the different grain size fractions. The grain size distribution for $\mathrm{CVC}$ and $\mathrm{SCC}$ was identical. A superplasticizer based on polycarboxylate-ether was used. The mix design is shown in Table II.

Table I. Composition of the different cement types (L.O.I. = loss on ignition, n.a. $=$ not analysed).

\begin{tabular}{|c|c|c|c|c|c|c|c|c|c|c|c|}
\hline Cement type & $\begin{array}{c}\mathrm{CaO} \\
{[\%]}\end{array}$ & $\begin{array}{c}\mathrm{SiO}_{2} \\
{[\%]}\end{array}$ & $\begin{array}{c}\mathrm{Al}_{2} \mathrm{O}_{3} \\
{[\%]}\end{array}$ & $\begin{array}{c}\mathrm{Fe}_{2} \mathrm{O} \\
3 \\
{[\%]}\end{array}$ & $\begin{array}{c}\mathrm{Mg} \\
\mathrm{O} \\
{[\%]}\end{array}$ & $\begin{array}{c}\mathrm{K}_{2} \mathrm{O} \\
{[\%]}\end{array}$ & $\begin{array}{c}\mathrm{Na}_{2} \\
\mathrm{O} \\
{[\%]}\end{array}$ & $\begin{array}{c}\mathrm{SO}_{3} \\
{[\%]}\end{array}$ & $\begin{array}{c}\text { Blaine } \\
{\left[\mathrm{cm}^{2} /\right.} \\
\mathrm{g}]\end{array}$ & $\begin{array}{c}\text { L.O. } \\
\mathrm{I} \\
{[\%]}\end{array}$ & $\begin{array}{c}\text { Densit } \\
\mathrm{y} \\
{\left[\mathrm{kg} / \mathrm{m}^{3}\right.} \\
]\end{array}$ \\
\hline $\begin{array}{c}\mathrm{CEM} \mathrm{I} \\
42.5 \mathrm{~N}\end{array}$ & 62.4 & 20.8 & 4.98 & 3.21 & 2.14 & 0.87 & 0.29 & 2.67 & 3100 & 2.98 & 3.13 \\
\hline $\begin{array}{c}\text { CEM II/B-M } \\
\text { (V-LL) } 32.5 \\
\mathrm{R}\end{array}$ & 52.5 & 23.1 & 7.31 & 3.56 & 2.14 & 1.19 & 0.39 & 2.55 & 4180 & n.a. & 2.90 \\
\hline $\begin{array}{c}\text { CEM III/B } \\
\text { 42.5 L-LH HS }\end{array}$ & 49.0 & 30.6 & 9.65 & 1.22 & 5.14 & 0.61 & 0.26 & 1.38 & 4500 & n.a. & 3.00 \\
\hline
\end{tabular}

Compressive strength, flexural strength and E-modulus were measured on prisms 120 x $120 \times 360 \mathrm{~mm}$ at the age of 2, 7 and 28 days. Creep and shrinkage were determined on prisms $120 \times 120 \times 360 \mathrm{~mm}$ up to the age of 91 days at $20^{\circ} \mathrm{C}$ and $70 \%$ relative humidity. The load for determining creep was applied after 2 days and readjusted after 7 and 28 days. The loads corresponded to $33 \%$ of the compressive strength of the specific concrete mixtures at the different ages. Creep was then calculated as the difference from total deformation minus elastic and shrinkage deformation. 
Table II. Mix design of CVC and SCC.

\begin{tabular}{|c|c|c|c|c|c|c|}
\hline Concrete & CVC-I & CVC-II & CVC-III & SCC-I & SCC-II & SCC-III \\
\hline Cement type & CEM I & $\begin{array}{c}\text { CEM } \\
\text { II/B-M }\end{array}$ & $\begin{array}{c}\text { CEM } \\
\text { III/B }\end{array}$ & CEM I & $\begin{array}{c}\text { CEM } \\
\text { II/B-M }\end{array}$ & $\begin{array}{c}\text { CEM } \\
\text { III/B }\end{array}$ \\
\hline $\begin{array}{c}\text { Cement content } \\
{\left[\mathrm{kg} / \mathrm{m}^{3}\right]}\end{array}$ & 320 & 320 & 320 & 520 & 520 & 520 \\
\hline $\begin{array}{c}\text { Aggregate } 0 / 32 \mathrm{~mm} \\
{\left[\mathrm{~kg} / \mathrm{m}^{3}\right]}\end{array}$ & 2016 & 1994 & 2003 & 1621 & 1584 & 1600 \\
\hline Water $\left[\mathrm{kg} / \mathrm{m}^{3}\right]$ & 128 & 128 & 128 & 208 & 208 & 208 \\
\hline SP $\left[\mathrm{kg} / \mathrm{m}^{3}\right]$ & 3.8 & 1.6 & 2.2 & 4.2 & 1.1 & 1.1 \\
\hline Paste volume $\left[1 / \mathrm{m}^{3}\right]$ & 230 & 238 & 235 & 378 & 392 & 386 \\
\hline $\mathrm{w} / \mathrm{c}$ & 0.40 & 0.40 & 0.40 & 0.40 & 0.40 & 0.40 \\
\hline
\end{tabular}

Stress caused by shrinkage under restrained conditions was measured in a steel frame referred to as "cracking frame". The cross-section of the concrete specimen used to measure the stress was $15 \times 15 \mathrm{~cm}$, the free length was $125 \mathrm{~cm}$. The specimen was anchored at both ends in the steel frame. When the concrete shrunk, the deformations were restrained by the steel frame. As a result, tensile stress developed in the concrete that equilibrated the compressive force on the two steel columns in the cracking frame. The deformation in the steel columns was determined using thin-film metal wire strain gauges. Based on these data, the tensile stress in the concrete specimen was calculated as a function of time. The measurements were started immediately after casting. The specimen was covered on three sides by the mould and the upper surface by a plastic sheet. After $24 \mathrm{~h}$, the mould and the plastic sheet were removed to expose the concrete to $20^{\circ} \mathrm{C}$ and $70 \%$ relative humidity. The entire cross-section of the specimen was supported at two points with rolls in order to prevent bending. The degree of restraint in the cracking frame is dependent on the E-modulus of the concrete and varied between 80 and $88 \%$ depending on the E-modulus of the specific concrete mixture.

Stress development of SCC I was determined twice in order to assess reproducibility. A maximum relative difference of $7 \%$ at the age of six days was measured. In the second mixture of SCC II, six sensors were embedded into the midsection of the specimen to measure the temperature gradient from the surface to the core of the specimen for the first $48 \mathrm{~h}$ after casting.

\section{Results}

\section{Mechanical Properties}

The concrete produced with CEM I shows the highest compressive strength after two days and the one produced with CEM III/B the lowest (Table III). At the age of 28 days, compressive strength of the different $\mathrm{CVC}$ varies in the range of $15 \%$, while the average compressive strength of SCC is about $20 \%$ lower. Flexural strength behaves in a similar way. The differences in E-modulus at 28 days caused by cement type are below $5 \%$, but SCC shows values approximately $20 \%$ lower than CVC. 
Table III. Compressive strength, flexural strength and E-Modulus of CVC and SCC.

\begin{tabular}{|c|c|c|c|c|c|c|c|c|c|}
\hline Mixture & $\begin{array}{c}\mathrm{f}_{\mathrm{c} 2 \mathrm{~d}} \\
{[\mathrm{MPa}]}\end{array}$ & $\begin{array}{c}\mathrm{f}_{\mathrm{c} 7 \mathrm{~d}} \\
{[\mathrm{MPa}]}\end{array}$ & $\begin{array}{c}\mathrm{f}_{\mathrm{c} 28 \mathrm{~d}} \\
{[\mathrm{MPa}]}\end{array}$ & $\begin{array}{c}\mathrm{f}_{\mathrm{f} 2 \mathrm{~d}} \\
{[\mathrm{MPa}]}\end{array}$ & $\begin{array}{c}\mathrm{f}_{\mathrm{f} 7 \mathrm{~d}} \\
{[\mathrm{MPa}]}\end{array}$ & $\begin{array}{c}\mathrm{f}_{\mathrm{f} 28 \mathrm{~d}} \\
{[\mathrm{MPa}]}\end{array}$ & $\begin{array}{c}\text { E-Mod } \\
{[\mathrm{GPa}]}\end{array}$ & $\begin{array}{c}\text { E-Mod } \\
{[\mathrm{dd}} \\
{[\mathrm{GPa}]}\end{array}$ & $\begin{array}{c}\text { E-Mod } 28 \mathrm{~d} \\
{[\mathrm{GPa}]}\end{array}$ \\
\hline CVC I & 36.8 & 60.7 & 71.8 & 5.2 & 6.3 & 7.9 & 33.8 & 41 & 42.8 \\
\hline CVC II & 28.9 & 50.1 & 62.3 & 4.9 & 5.5 & 7.8 & 30.6 & 38.4 & 41.2 \\
\hline CVC III & 23.4 & 51.2 & 73 & 4.2 & 6.4 & 8.6 & 29.2 & 36.0 & 43.4 \\
\hline SCC I & 32.5 & 53.5 & 61.4 & 4.8 & 4.7 & 6.4 & 28.5 & 33.2 & 34.2 \\
\hline SCC II & 27.4 & 41.7 & 50.9 & 4.4 & 4.2 & 5.9 & 28.2 & 31.9 & 35.1 \\
\hline SCC III & 15.2 & 38.5 & 51.3 & 3.5 & 4.2 & 5.5 & 19.9 & 28.2 & 33.8 \\
\hline
\end{tabular}

\section{Shrinkage and Creep}

SCC shrinks considerably more than CVC (Fig. 1). The average at 91 days differs by $0.18 \%$ (absolute value) and 40\% (relative value) respectively. The concrete produced with CEM I shrinks more than CEM II/B-M or CEM III/B concrete. While the progress of shrinkage with time is similar for concrete produced with CEM I and CEM II/B-M, CVC III and SCC III exhibit a high shrinkage rate during the first 14 days and remarkably low shrinkage rates after 28 days. Mass loss of SCC is higher (Fig. 2) but differences between $\mathrm{CVC}$ and SCC are less pronounced than for shrinkage. CVC I and SCC I show the lowest mass loss for their specific type of concrete.

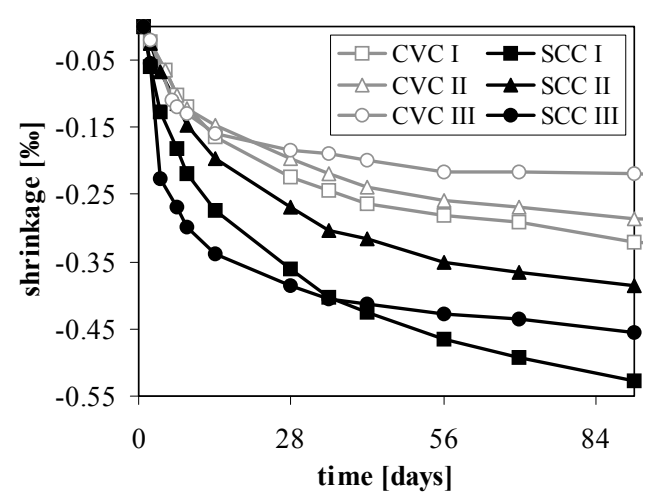

Figure 1. Shrinkage as a function of time.

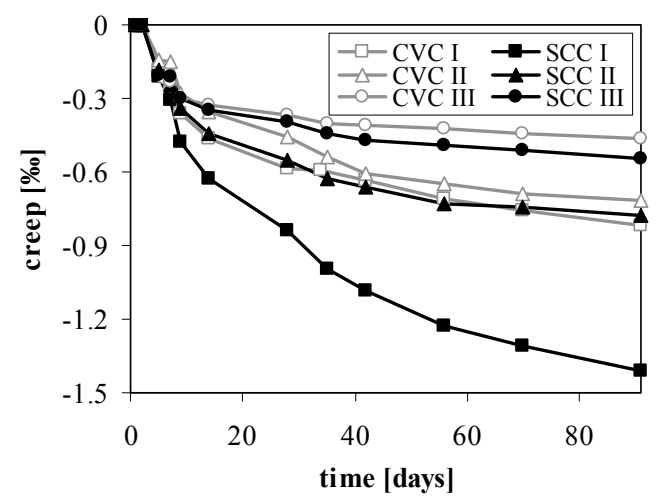

Figure 3. Creep as a function of time.

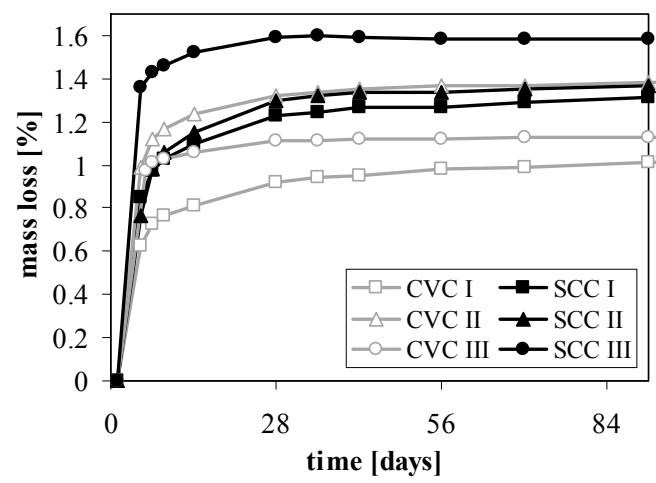

Figure 2. Mass loss as a function of time.

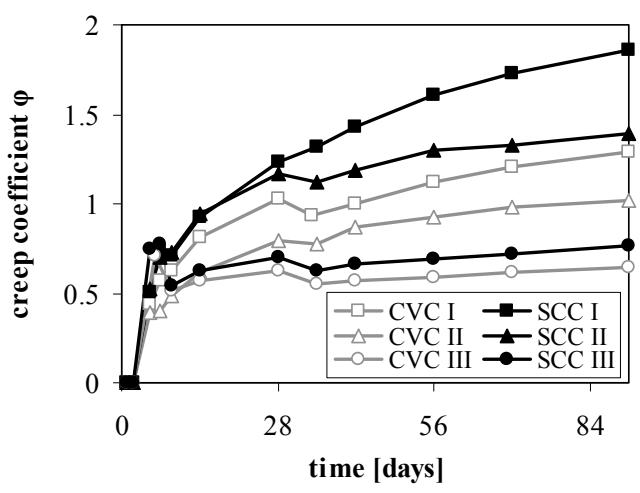

Figure 4. Creep coefficient as a function of time. 
Creep of SCC II and SCC III is slightly higher compared to their CVC counterpart, while SCC I creeps considerably more than CVC I (Fig. 3). Creep coefficient $\varphi$ of $\mathrm{SCC}$ is higher compared to CVC and it decreases going from concrete produced with CEM I to CEM II/B-M and finally CEM III/B (Fig. 4).

\section{Restrained Shrinkage}

The peak temperature in SCC I is reached after 14 hours (Fig. 5), when the stress in the concrete is negligible. During cooling, stress measurements indicate a short period of expansion (2-3 hours) before tensile stress develop at a fast rate (Fig. 5 ). 24 hours after casting, the specimen is demolded, causing an even faster stress increase. A deceleration is then observed leading to a period between 30 and 46 hours with only minor changes in stress. At the end of this period, the stress starts to rise steadily.

SCC shows a faster stress development compared to CVC, resulting in higher stress values already after two days (Fig. 6). The only exception is SCC II, whose stress level is similar to CVC II and only after 7 days shows a higher increase. SCC III, SCC I and SCC II show the highest stresses and crack after 3.5, 9 and 16 days respectively. While stress increase of the three SCC mixtures clearly differs, CVC I and II show only minor differences up to an age of 8 days. Afterwards, stress of CVC I decreases less compared to CVC II. CVC III initially shows higher values than the other CVC. However, as its stress gradient is lower than the one of CVC II, the two curves intersect at 25 days.

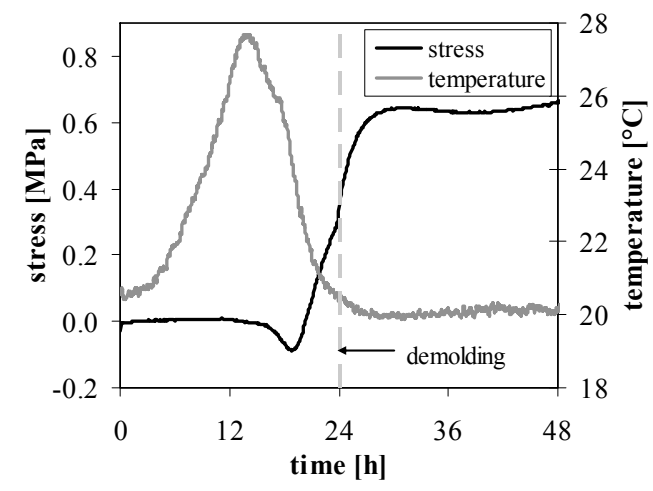

Figure 5. Development of stress and temperature (concrete depth of $5.5 \mathrm{~cm}$ ) as a function of time.

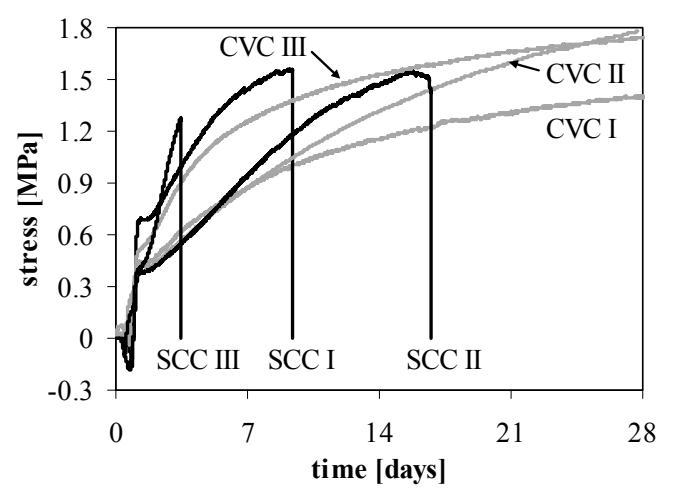

Figure 6. Stress increase of CVC and $\mathrm{SCC}$ as a function of time.

\section{Discussion}

\section{Experimental Results}

The lower strength of SCC compared to CVC despite having an identical w/c is caused by the different amount of aggregates used. Dry aggregates absorb water due to their porosity and as such reduce the amount of water available for cement hydration. As more water is absorbed in the aggregates of $\mathrm{CVC}$, the resulting 
compressive strength is higher. Another factor playing a role is the different strength of the paste and the aggregate, which both contribute to the strength of the concrete. Shrinkage is dominated by the volume of paste, with cement type having a lower influence [1-6]. However, when the different SCC are compared, it is obvious that choice of cement type is important for shrinkage rate and total shrinkage. When curing time is short ( $\leq 2$ days) SCC I and II seem to be better suited for concrete exposed to drying at a relatively early age (e.g. slabs, decks) than SCC III which shrinks very fast during the first days. When prolonged curing (at least 7 days) is possible, SCC III offers the benefit of low shrinkage rates at later ages.

There seems to be no correlation between shrinkage and mass loss of the different mixtures. As an example, SCC I and II show considerable differences in shrinkage, while mass loss is identical. However, when shrinkage and mass loss relative to the values at 91 days are plotted, a clear relation between these two parameters is found (Fig. 7). Shrinkage strain is governed by capillary forces that depend on the relative humidity in the pore system, the pore size distribution and their change with ongoing hydration and water loss to the environment. Differences in paste volume and cementspecific pore systems lead to different shrinkage strains. But the relation in time between shrinkage strain and mass loss seems to be the same for all concrete mixtures.

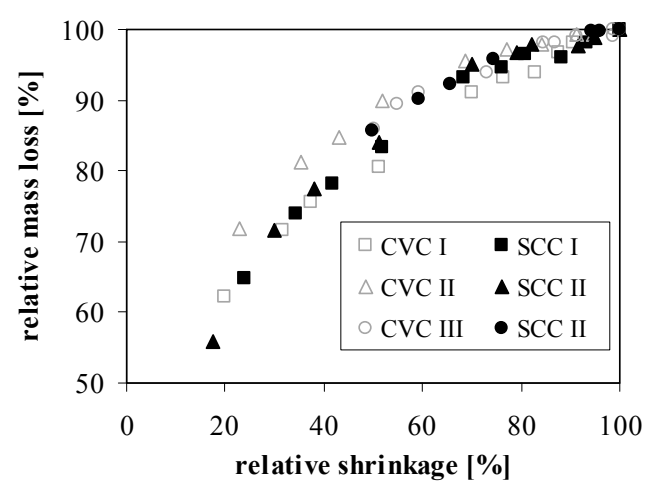

Figure 7. Relative mass loss to the value at 91 days as a function of relative shrinkage to the value at 91 days.

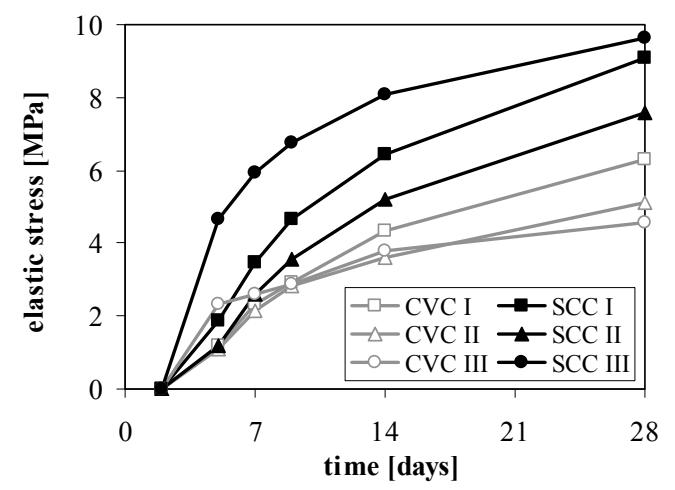

Figure 8. Calculated elastic stress of CVC and SCC as a function of time.

Creep and creep coefficient are considerably less affected by paste volume than shrinkage. Both CVC and SCC show a decrease of creep and creep coefficient with decreasing clinker content, leading to the lowest values for CVC III and SCC III. Differences between the concrete mixtures which could affect creep are the cementspecific amount of hydration products and the composition of the hydrates [10].

Development of elastic stress under restrained conditions can be calculated based on Eqn. 1 using the experimentally determined values for shrinkage and E-modulus:

$$
\sigma_{s}=k \cdot E \cdot \varepsilon_{s t}
$$

where $\quad \sigma_{\mathrm{s}}=$ shrinkage stress

$\varepsilon_{s t}=$ total shrinkage 


$$
\begin{aligned}
& k=\text { degree of restraint } \\
& E=\text { E-modulus }
\end{aligned}
$$

Creep is not considered in Eqn. 1, leading to the difference between experimentally determined and calculated values. Elastic stress of SCC is considerably larger compared to CVC (Fig. 8). The cement-specific development of elastic stress correlates to the experimentally determined stress. SCC III shows the fastest increase followed by SCC I and SCC II. Development of calculated and measured stress of CVC, however, does not correlate. In relation the other $\mathrm{CVC}, \mathrm{CVC}$ I results in the highest calculated elastic stress but the lowest stress is measured for this concrete after 28 days. CVC I shows the highest creep and creep coefficient of the CVC mixtures, most likely leading to the highest degree of relaxation. Although SCC shows somewhat higher creep than CVC, relaxation may influence the measured stress less than the magnitude of free shrinkage. In fact, due to the high shrinkage rate, stress develops very fast and creep-induced relaxation has less time to occur. The effect of creep on stress and risk of cracking increases when shrinkage rates are low [3].

The effect of hydration heat on stress can be neglected as temperature has nearly decreased to room temperature when stress starts to rise (Fig. 5). The expansion observed a few hours after casting has to be regarded as an effect of cement hydration not directly related to temperature. The characteristic curve shape between 1 and 2 days with a slight decrease of stress may be the result of the interplay between relaxation caused by creep and shrinkage. In fact, in a model for restrained shrinkage that incorporates a relaxation term, a curve with identical shape was obtained [11].

\section{Modeling}

As observed in the previous sections, one reason for differences in E-modulus, creep and shrinkage of SCC and CVC is the different paste and aggregate content. In this section, composite models are used to predict E-modulus and shrinkage of a SCC based on measurements performed on a CVC with the same cement paste.

The following equation developed by Hobbs $[12,13]$ allows calculating the Emodulus of a concrete based on the E-modulus of matrix and aggregates:

$$
E_{C}=\frac{\left(E_{A}-E_{M}\right) \cdot \phi_{A}+E_{A}+E_{M}}{E_{A}+E_{M}+\phi_{A} \cdot\left(E_{M}-E_{A}\right)} \cdot E_{M}
$$

where $E_{A}=$ the E-modulus of the aggregates [GPa]

$E_{M}=$ the E-modulus of the matrix [GPa]

$\phi_{A}=$ the volume fraction of the aggregates $\left[\mathrm{m}^{3} / \mathrm{m}^{3}\right]$

Eqn. 2 provides rather accurate E-modulus predictions [14] and can be solved numerically to derive the value of $E_{M}$, the E-modulus of the cement paste. Leemann and Lura [15] used this approach to calculate the E-modulus of the cement paste of a SCC and a CVC at 2, 7 and 28 days. Furthermore, when the E-modulus of the cement paste is derived from measurements on a $\mathrm{CVC}$, it can be used to calculate the Emodulus of a SCC with the same cement paste. Fig. 9 shows the measured E-modulus at 2, 7 and 28 days for the CVC and SCC mixtures, together with the E-modulus of the SCC calculated with Eqn. 4.2. $60 \mathrm{GPa}$ was assumed as E-modulus of the 
aggregates, while the volume fractions of the aggregate can be derived from Table II. For SCC I and SCC III, the average difference between measured and calculated values is lower than 5\%, while for SCC II it is about $10 \%$. Consequently, the Emodulus of the SCC mixtures appears to be mainly a consequence of the higher cement paste content of these mixtures and can be calculated with good approximation knowing the E-modulus of the corresponding CVC.

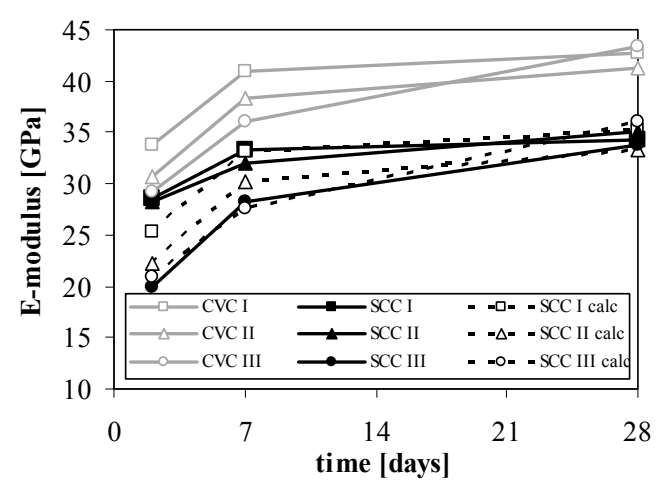

Figure 9. Measured E-modulus of CVC and SCC and calculated E-modulus of SCC based on Eqn. 2.

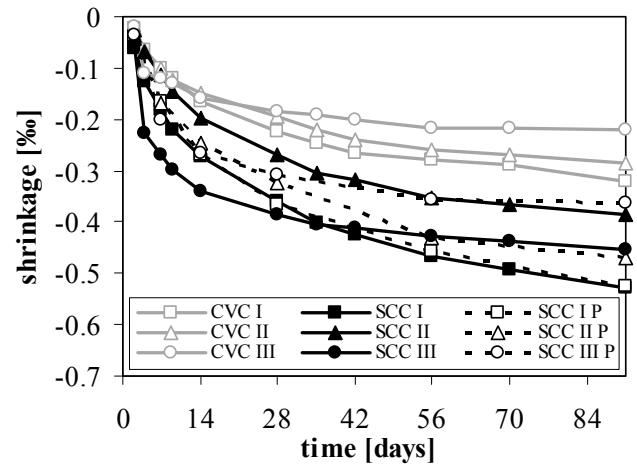

Figure 10. Shrinkage of three CVC and corresponding SCC and shrinkage of SCC calculated with Pickett's model.

In the following, the shrinkage of the SCC mixtures is calculated based on a composite model and on the shrinkage of the corresponding CVC. More information about calculation of shrinkage with composite models can be found in [14]. Pickett [16] derived the following expression for the effects of aggregates on concrete shrinkage:

$$
\varepsilon_{C}=\varepsilon_{P} \cdot\left(1-\phi_{A}\right)^{\alpha_{P}}
$$

where $\varepsilon_{C}=$ the shrinkage of concrete $[\mathrm{m} / \mathrm{m}]$

$\varepsilon_{P}=$ the shrinkage of the paste $[\mathrm{m} / \mathrm{m}]$

$\phi_{A}=$ the volume fraction of the aggregates $\left[\mathrm{m}^{3} / \mathrm{m}^{3}\right]$

$\alpha_{P}=$ a parameter [-], defined as:

$$
\alpha_{P}=\frac{3 \cdot\left(1-v_{C}\right)}{1+v_{C}+2 \cdot\left(1-2 v_{A}\right) \cdot E_{C} / E_{A}}
$$

where $v_{C}$ and $v_{A}=$ the Poisson's ratio of the concrete and of the aggregates, respectively [-]

$E_{C}$ and $E_{A}=$ the E-moduli of the concrete and of the aggregates, respectively [GPa]

Since both $\varepsilon_{P}$ and $E_{C}$ vary in time, shrinkage as a function of time can be calculated by integrating in time a differential form of Eqn. 3 (see [14]).

Pickett's model can be used to calculate the shrinkage of a SCC if the shrinkage and the E-modulus of a CVC with the same cement paste (i.e., same type of cement and 
same w/c) are known. $E_{C}$ in Eqn. 4 has been measured as a function of time for the CVC and can be calculated with Eqn. 2 for the SCC (Fig. 10). $v_{C}$ is roughly constant in time and can be assumed as 0.2. The same value is taken for $v_{A}$, while for $E_{A}=60$ GPa can be assumed. Two separate coefficients, $\alpha_{P, C V C}$ and $\alpha_{P, S C C}$ can thus be obtained, which both depend on time through $E_{C V C}$ and $E_{S C C}$. However, for the concrete mixtures used in this study, $\alpha_{P}$ varies generally less than $10 \%$ and at most $15 \%$ for SCC III between 2 and 28 days. We will therefore consider it constant in time to simplify the calculations. Eqn. 3 can be thus written both for the CVC and the SCC in the differential form:

$$
\begin{aligned}
& d \varepsilon_{C V C}(t)=d \varepsilon_{P}(t) \cdot\left(1-\phi_{A, C V C}\right)^{\alpha_{P, C V C}} \\
& d \varepsilon_{S C C}(t)=d \varepsilon_{P}(\xi) \cdot\left(1-\phi_{A, S C C}\right)^{\alpha_{P, S C C}}
\end{aligned}
$$

As $\varepsilon_{P}$ is supposed to be the same in the CVC and SCC based on the same paste, it can be eliminated from Eqns. 5 and 6, thus yielding Eqn. 7, and finally integrated to obtain the shrinkage in time of SCC (Eqn. 8):

$$
\begin{gathered}
d \varepsilon_{S C C}(t)=d \varepsilon_{C V C}(t) \cdot \frac{\left(1-\phi_{A, C V C}\right)^{\alpha_{P, C V C}}}{\left(1-\phi_{A, S C C}\right)^{\alpha_{P, S C C}}} \\
\varepsilon_{S C C}(t)=\int_{0}^{t} d \varepsilon_{C V C}(\xi) \cdot \frac{\left(1-\phi_{A, C V C}\right)^{\alpha_{P, C V C}}}{\left(1-\phi_{A, S C C}\right)^{\alpha_{P, S C C}}} d \xi
\end{gathered}
$$

Fig. 10 shows the shrinkage the three CVC and SCC mixtures together with calculations of SCC shrinkage according to Pickett's model. While the prediction for SCC I is remarkably close to the experimental results, the shrinkage of SCC II is overestimated and the shrinkage of SCC III is underestimated. The errors for SCC II and III are large in the first few days, while the predictions at later ages ( $>7$ or 14 days) have a maximum error of about $25 \%$ and can be considered satisfactory. The poor performance of the composite models at early ages may be due to different kinetics of drying and shrinkage in concrete mixtures with different amount of cement paste. Another reason for this difference may be the pronounced visco-elastic behaviour of concrete at early ages, which is not taken into account in the composite models [14].

\section{Conclusions}

The influence of paste volume and binder composition on shrinkage, creep, mechanical properties and stress development under restrained conditions of CVC and SCC with identical w/c were investigated.

In spite of identical w/c, compressive and tensile strength of $\mathrm{CVC}$ are higher, likely due to the higher amount of water absorbed by the aggregates. SCC shows a lower ratio between E-Modulus and compressive strength due to the higher paste volume. While shrinkage is mainly dominated by paste volume, with higher values for SCC compared to $\mathrm{CVC}$, the differences in total shrinkage and shrinkage rate caused by the 
use of different cement types are still substantial. In contrast to shrinkage, the influence of cement type on creep and creep coefficient is at least the same or even larger than the influence of paste volume. Differences in tensile stress build-up under restrained conditions are dominated by shrinkage of the different mixtures, with differences in creep playing a secondary role. Consequently, stress of SCC is higher compared to CVC.

Simple analytical composite models prove that the lower E-modulus and higher shrinkage of the SCC mixtures are due to their higher paste volume. The predictions of E-modulus of SCC based on the modulus of CVC are rather accurate, generally within $5 \%$ and with a maximum error of $10 \%$. The predictions of shrinkage based on Pickett's model show large errors at early ages, but are generally within $25-30 \%$ at later ages. Similar composite models can be developed also to study creep of concrete. Finally, by combining results for E-modulus, creep and shrinkage, it is expected that composite models can be used to predict the different cracking risk of SCC and CVC.

\section{References}

[1] Rozière, E., Granger, S., Turcry, P. and Loukili, A. (2007), Cem. Conc. Comp., vol. 29, pp. 626-636

[2] Ghoddousi, P. and Monir Abbasi, A. (2008), 3rd North American Conference on the Design and Use of Self-Consolidating Concrete, Chicago.

[3] Loser, R. and Leemann, A. (2009), Mater. Struct., vol. 42, pp. 71-82.

[4] Poppe, A.M. and De Schutter, G. (2005), In: 1st International Symposium on Design, Performance and Use of SCC, Yu, Z., Shi, C., Khayat, K.H. and Xie, Y. (Eds), RILEM Publications SARL, France, pp. 329-336.

[5] Khatib, J.M. (2008), Const. Build. Mater., vol. 22, pp. 1963-1971.

[6] Gesoğlu, M., Güneyisi, E. and Özbay, E. (2009), Const. Build. Mater., vol. 23, pp. 1847-1854

[7] Heirman, G., Vandewalle, L., Van Gemert, D., Boel, V., Audenaert, K., De Schutter, G., Desmet, B. and Vantomme, J. (2008), Eng. Struct., vol. 30, pp. 2945-2956.

[8] Turcry, P. and Loukili, A. (2006), ACI Mat. J., vol. 103, pp. 272-279.

[9] Vieira, M. and Bettencourt, A. (2003), 3rd International Symposium on SCC, Reykjavik, pp. 637-644.

[10] Richardson, I.G., Brough, A.R., Groves, G.W. and Dobson, C.M. (1994), Cem. Concr. Res., vol. 24, pp. 813-829.

[11] Dela, B.F. (2000), Doctoral thesis, Department of Structural Engineering and Materials, Technical University of Denmark, Series R, No 64.

[12] Hobbs, D.W. (1969), Nature, vol. 222, pp. 849-851.

[13] Hobbs, D.W. (1974), ACIJ., vol. 71, pp. 445-450.

[14] Lura, P. (2003), PhD Thesis, Delft University of Technology.

[15] Leemann, A. and Lura, P. (2010), In: State-of-the-Art report of RILEM Technical Committee MPS: Mechanical properties of self-compacting concrete, Khayat, K.H. and De Schutter, G. (Eds), RILEM Publications S.A.R.L.

[16] Pickett, G. (1956), ACI J. Proc., vol. 52, pp. 581-590. 